\title{
Foot and Mouth Disease: Carrier Status
}

\section{Rajeev Ranjan* and Jitendra Kumar Biswal}

ICAR-International Centre for Foot and Mouth Disease, Bhubaneswar, Odisha, India

*Corresponding Author: Rajeev Ranjan, Scientist, ICAR-International Centre for Foot and Mouth Disease, Bhubaneswar, Odisha, India.

DOI: $10.31080 /$ ASVS.2022.03.0228

Foot and mouth disease (FMD) is an acute, contagious viral disease that affects cloven-hooved domestic animals as well as over 70 wild life species such as elephants, deer etc. Symptoms of the disease include pyrexia, lameness, and vesicular lesions of the tongue, feet, muzzle, and teats [9]. Following a subset of the acute phase of infection, 50- 60\% of the bovine population becomes a carrier or is persistently infected with FMD virus (FMDV). A carrier animal is one from which infectious FMDV virus [10] or genome detection [6] can be recovered 28 days after FMDV infection in the oropharyngeal fluid (OPF). FMDV persistence varies by species [2] and can occur in both vaccinated and unvaccinated animals [1]. Few researchers have previously reported that FMDV can be transmitted from carrier animals to susceptible naive populations under field conditions [8] or experimental conditions [5] and this could be due to the presence of infectious FMDV in oropharyngeal fluid of seemingly healthy animals $[4,7]$.

There is a scarcity of literature dealing with the emergence, persistence, and existence of FMDV persistence or carrier state in bovine populations, either naturally or experimentally. FMDV control and eradication programmes in endemic settings are frequently complicated due to the virus's high contagiousness, wide host range, persistence, transboundary and quasi species nature $[3,11]$. Although the role of persistently infected animals in causing new FMD outbreaks is unknown, the OIE's international FMD standards state that countries must demonstrate freedom from FMDV-infection in order to achieve/regain FMD-free status. As a result, FMD-free countries have generally kept trade barriers in place on animals and animal products from countries that have not demonstrated FMDV infection freedom, including the absence of persistently infected animals.
Received: June 21, 2021

Published: October 01, 2021

(C) All rights are reserved by Rajeev Ranjan and Jitendra Kumar Biswal.
I conclude that a detailed study of host pathogen interaction, evasion of host immune response, establishment of FMDV persistence or carrier state, antigenic variation, and other topics in bovine populations is required for effective control followed by eradication of FMD in endemic settings.

\section{Bibliography}

1. Alexandersen S., et al. "Aspects of the persistence of foot-andmouth disease virus in animals-the carrier problem". Microbes and Infection 4.10 (2002): 1099-110.

2. Alexandersen S., et al. "The pathogenesis and diagnosis of footand-mouth disease". Journal of Comparative Pathololgy 129 (2003): 1-36.

3. Arzt J., et al. "The pathogenesis of foot-and-mouth disease II: viral pathways in swine, small ruminants, and wildlife, myotropism, chronic syndromes, and molecular virus-host interactions". Transboundary and Emerging Disease 58 (2011): 305326.

4. Arzt J., et al. "Transmission of foot-and mouth disease from persistently infected carrier cattle to naive cattle via transfer of oropharyngeal fluid". mSphere 3 (2018): e00365-318.

5. Bao HF., et al. "The infectivity and pathogenicity of a foot-andmouth disease virus persistent infection strain from oesophageal-pharyngeal fluid of a Chinese cattle in 2010". Journal of Virology 8 (2011): 536.

6. Donn A., et al. "Improved detection of persistent foot-andmouth disease infection in cattle by the polymerase chain reaction". Journal of Virological Methods 49 (1994): 179-186.

7. Hayer SS., et al. "Quantitative characteristics of the foot-andmouth disease carrier state under natural conditions in India". Transboundary and Emerging Disease 65.1 (2018): 253-260. 
8. Klein J. "Understanding the molecular epidemiology of footand mouth- disease virus". Infection, Genetics and Evolution 9.2 (2009): 153-161.

9. Ranjan R., et al. "Managements of Foot and Mouth Disease in a dairy farm: By Ethnoveterinary practice". Indian Journal of Animal Sciences 86.3 (2016): 256-259.

10. Sutmoller P and Gaggero A. "Foot-and-mouth diseases carriers”. Veterinary Record 77.33 (1965): 968-969.

11. World Organisation for Animal Health (OIE). Terrestrial Animal Health Code, Chapter 8.8. "Infection with foot and mouth disease virus". World Organisation for Animal Health (OIE), Paris, France.

Volume 3 Issue 11 November 2021

(C) All rights are reserved by Rajeev Ranjan and Jitendra Kumar Biswal. 